\title{
Evaluation questionnaire for GRAI-GIM
}

\author{
Task Force
}

12.1 ARCHITECTURE $^{1}$ (All answers in italics)

\subsubsection{Users of the architecture}

What is the intended/targeted audience of this architecture?

Consultants, designers of manufacturing systems in various companies. Any decision maker related to manufacturing systems.

\subsubsection{Intended scope of architecture}

Please check those activities which are in the intended scope of the architecture (in the short term, i.e. 2-3 years)

\begin{tabular}{|c|c|c|c|}
\hline $\begin{array}{c}{[]} \\
\text { covered } \\
\text { context }\end{array}$ & $\begin{array}{c}{[]} \\
\text { partially cov- } \\
\text { ered context }\end{array}$ & $\begin{array}{c}{[]} \\
\text { context not } \\
\text { covered }\end{array}$ & $\begin{array}{c}{[]} \\
\text { no } \\
\text { information }\end{array}$ \\
\hline
\end{tabular}

Example

[ ] [ ] [x] [ ] product research and development

[ ] [ ] [x] [ ] customer services, product maintenance

[ ] [x] [ ] [ ] product management, marketing function, strategic

[ ] [x] [ ] [ ] product distribution

[ ] [ ] [x][ ] marketing

[ ] [x] [ ] [ ] product design

[x] [ ] [ ] [ ] production planning

[x] [ ] [ ] [ ] manufacturing control

[ ] [x] [ ] [ ] manufacturing

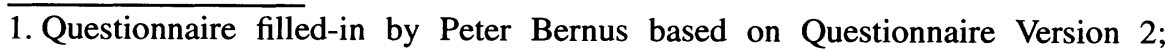
answers provided by Bruno Vallespir and corrected by Guy Doumeingts and Laszlo Nemes at the Toronto Task Force Meeting (May 1992) 
[ ] [x] [ ] [ ] material handling, storage and transport

[]$[x][][]$ testing and quality control

[ ] [x][ ] [ ] logistics

[ ] [x][ ] [ ] acquisition

[ ] [ ] [x] [ ] legal services

[ ] [ ] [x] [ ] personnel services finance, accounting

[ ] [x] [ ] [ ] infrastructure, archiving and library services

[ ] [x] [ ] [ ] infrastructure, communications (excluding computer communications)

[ ] [x] [ ] [ ] information technology infrastructure, including computer communications, computing, database management, etc.

$[\mathrm{]}[\mathrm{x}][\mathrm{]}] \mathrm{]}$ education

[ ] [x] [ ] [ ] strategic enterprise management

[ ] [ ] [x][ ] market research

$[\mathrm{x}][\mathrm{]}][\mathrm{]}] \mathrm{]}$ resource management

[x] [ ] [ ] [ ] factory development (development of the production facility)

[ ] [x] [ ] [ ] project management

$[\mathrm{x}][\mathrm{]}][\mathrm{]}] \mathrm{]}$ factory design

[ ] [ ] [x] [ ] factory building and modernization

$[\mathrm{J}][\mathrm{x}][\mathrm{]}]$ factory maintenance

[ ] [ ] [x][ ] infrastructure, energy

[ ] [ ] [x] [ ] infrastructure, buildings and grounds

[x] [ ] [ ] [ ] other (please specify): maintenance

\subsubsection{What is the highest intended level of genericity on which this architecture is applicable? (check one)}

[ ] every type of enterprise

[x] certain type of industry (please specify which one)?

(Industrial enterprise)

What is the area of industry in which the architecture has already been applied? discrete part manufacturing 
12.1.4 Which stage of systems development is addressed by the architecture? (multiple choice question)

\begin{tabular}{|c|c|c|c|}
\hline $\begin{array}{l}\text { [] fully } \\
\text { covered }\end{array}$ & $\begin{array}{c}\text { [] partially } \\
\text { covered }\end{array}$ & {[] not covered } & $\begin{array}{c}\text { [] no } \\
\text { information }\end{array}$ \\
\hline
\end{tabular}

Example
[x] [ ] [ ] [ ] requirements
$[\mathrm{x}][\mathrm{]}[\mathrm{]}[\mathrm{]}$ implementation (configuration and reconfiguration)
$[\mathrm{]}[\mathrm{x}][\mathrm{]}] \mathrm{]}$ design
$[\mathrm{b}][\mathrm{]}][\mathrm{]}$ operation and maintenance

\subsubsection{What are the goals which we would like to attain by developing generic CIM architectures? (Which are the main factors of industry's need?)}

(Please concentrate on the user requirements of a prospective utilizing industry.)

\begin{tabular}{|c|c|c|c|}
\hline $\begin{array}{c}\text { [] essential } \\
\text { factor }\end{array}$ & $\begin{array}{c}\text { [] important } \\
\text { factor }\end{array}$ & $\begin{array}{c}\text { [] advanta- } \\
\text { geous but not } \\
\text { essential }\end{array}$ & $\begin{array}{c}\text { [] not } \\
\text { important }\end{array}$ \\
Example \\
\hline
\end{tabular}

[x] [ ] [ ] [ ] better use of current resources

$[\mathrm{]}[\mathrm{x}][\mathrm{]}][\mathrm{]}$ integration of current technology

[x] [ ] [ ] [ ] cutting excessive costs of having to develop CIM systems individually

[x] [ ] [ ] [ ] improve the quality of the developed individual systems/ manufacturing systems/CIM systems, etc.

[ ] [x] [ ] [ ] enabling the development of a marketplace for compatible CIM products

[ ] [ ] [x] [ ] decrease response/product cycle time

[ ] [x] [ ] [ ] contain metrics for exploring economic/technological options

[x] [ ] [ ] [ ] decisional integration

$[\mathrm{x}][\mathrm{]}][\mathrm{]}] \mathrm{]}$ understanding and training

[x] [ ] [ ] [ ] economic aspects

[ ] [x] [ ] [ ] obtain flexibility in system and adaptation to change in requirements

[x] [ ] [ ] [ ] Other (please specify) develop integration concepts between people

[x] [ ] [ ] [ ] promote development of manufacturing system documentation 


\subsubsection{De facto scope and detail}

This question is about how completely the architecture has been defined relative to its intended scope (see Question 2) and its intended detail.

You will have by now a few projects which have already used one part or another of this architecture. We would like to have a list of those activities which were covered by these projects and see what is the level of maturity of the models available (industry mature models, feasibility tested models of individual systems, developed generic models).

In the view of Guy Doumeingts this question should be reformulated. The following information is as it appeared in the response by Bruno Vallespir (GRAI Lab) in the Version 2 of this questionnaire.

Industry mature models: over a hundred individual production management case studies which produced decisional models of production planning and manufacturing control

Feasibility tested models of individual systems: Production planning (business planning and master production schedule) for electronic assembly of printed wiring boards; Manufacturing control (factory control).

Developed generic models: Information/decision/function aspects of strategic enterprise management

\subsubsection{Omissions}

(a) Please check and give details if needed):

[ ] the architecture covers its promised intended scope

[ ] the architecture omits some necessary detail (please specify the additional detail the architecture should provide)

GRAI takes into account the economic aspects through its ECOGRAI method. The human aspect is partially/indirectly taken into account in the decisional and organizational models/aspects.

(b) If you indicated a need for extension, could you name here any other architecture and model which does cover the missing detail (give specifics)

It has been suggested that one way to extend GRAI/GIM is to accommodate it in the Purdue Architecture. GRAI Lab (Doumeingts) suggests that this might be one of the possible ways. 


\subsubsection{Redundancy}

Does this architecture require that existing standards must be re-written (e.g. expressed in a new form without changing the content) in order to fit this architecture?

We do not know. Perhaps we bring something for standardization in the decisional aspect.

\subsubsection{System extensibility}

How do you ensure that systems created according to this architecture are open ended?

The architecture was conceived for tackling both new system development and modular evolution or reorganization of old systems into an integrated system.

If you judged that the architecture allows modular evolution, is this judgement based on

[x] theoretical considerations

[x] feasibility study or pilot project

[x] repeated industry experience

\subsubsection{Resilience}

Does the architecture provide any principles or guidance that will help the user to limit the effect of imposed external changes on the operation of the system?

The effect of changes is taken into account from the technical and from the organizational point of view. GRAI-GIM allows the change of the organization (taking into account possible constraints which exist in the given company).

\subsubsection{Skills required to implement}

Does the architecture adequately treat the skills required by the user to allow for the design and building of a specific system described by it? (give rating):

[x] $\operatorname{good}^{\mathrm{a}}$ 
a.The architecture is very good from this respect if the skills required are available or there are tried and natural, pragmatic ways for practitioners to extend their skills in the new direction.

\subsubsection{Dependence on new technologies}

Does the implementation of this architecture require a given type of new technology for any application within the scope? (A technology is new in this respect if it has not yet been proven under industrial circumstances).

[ ] no new technology required

[x] yes (please specify what new technology is involved) e.g.

[x] distributed relational databases

[ ] distributed object oriented databases

[ ] OSI communication

[ ] Open Distributed Processing Platform

[x] others (please specify)

Al techniques (for decision support)

High level fourth generation languages (4 GL)

12.1.13 What is your opinion about the future prospects for this architecture?

\begin{tabular}{|c|c|c|c|}
\hline[] & {[]} & {[]} & {[]} \\
yes, widespread & yes, limited area & no & undecided \\
\hline
\end{tabular}

Example

[x] [ ] [ ] [ ] will have theoretical impact

$[\mathrm{]}[\mathrm{x}][\mathrm{]}[\mathrm{]}$ will gain industry acceptance in the present form

[x] [ ] [ ] [ ] will gain industry acceptance in developed (or modified) fo

[x] [ ] [ ] [ ] other (please specify)

Development of an 'Implementation Manual' or 'Users Guide'

12.1.14 What were the reasons for the development of this architecture?

\begin{tabular}{|c|c|c|c|}
\hline $\begin{array}{c}\text { main } \\
\text { reason } \\
{[]}\end{array}$ & cofactor & $\begin{array}{c}\text { not a known } \\
\text { reason } \\
{[]}\end{array}$ & $\begin{array}{c}\text { no information } \\
{[]}\end{array}$ \\
\hline
\end{tabular}

Example

[ ] [ ] [x] [ ] utilization in a given segment of industry

[ ] [ ] [x] [ ] development of a national standard 
[ ] [ ] [x] [ ] development of an international standard

[ ] [ ] [x] [ ] utilization by a given firm

[x] [ ] [ ] [ ] utilization by a group of firms (1985)

[ ] [x] [ ] [ ] utilization for teaching purposes

[ ] [ ] [x] [ ] utilization for research purposes (1977)

[ ] ] [ ] [ ] [ ] Others: to solve a problem by a given firm (1980)

\subsubsection{What is the driving force behind this architecture?}

\begin{tabular}{|c|c|c|c|}
\hline $\begin{array}{c}{[]} \\
\text { main reason }\end{array}$ & $\begin{array}{c}{[]} \\
\text { cofactor }\end{array}$ & $\begin{array}{c}{[] \text { not a known }} \\
\text { reason }\end{array}$ & $\begin{array}{c}{[] \text { no }} \\
\text { information }\end{array}$ \\
\hline
\end{tabular}

[x] [ ] [ ] [ ] technology pull (there was a percieved need in industry for which the generic architecture intends to be the answer)

[ ] [x] [ ] [ ] technology push (results in the areas of architectures, methodologies, information technology, communications, manufacturing technology created opportunity or incentive for industry to develop this generic CIM architecture)

Please expand your views on the above quesion if possible.

The GIM architectural approach has developed as an extension to the GRAI method which has been a very successful technique to analyse and specify decisions on multiple levels of the control hierarchy in CIM (production management, planning, control).

\subsubsection{Adequacy}

Please rate the adequacy of the architecture with respect to the help which it provides for attaining the essential or important goals which you identified in Question 5.

\begin{tabular}{|c|c|c|c|c|}
\hline poor & average & good & excellent & no info. \\
[] & {[]} & {[]} & {[]} & {[]} \\
\hline
\end{tabular}

Example

[ ] [ ] [x] [ ] [ ] better use of current resources

[ ] [ ] [x] [ ] [ ] integration of current technology

[ ] [ ] [ ] [x] [ ] cutting excessive costs of having to develop CIM systems individually

[ ] [ ] [x] [ ] [ ] improve the quality of the developed individual systems/ manufacturing systems/CIM systems etc.

[x] [ ] [ ] [ ] [ ] enabling the development of a marketplace for compatible CIM products 
[ ] [x] [ ] [ ] [ ] decrease response/product cycle time

[ ] [ ] [x] [ ] [ ] contain metrics for exploring economic/technological options

[ ] [ ] [ ] [x] [ ] decisional integration

$[$ [ [ ] [ ] $[\mathrm{x}][$ ] understanding and training

[ ] [ ] [x] [ ] [ ] economic aspects

[ ] [ ] [x] [ ] [ ] obtain flexibility in system configuration and adaptation to change in requirements

[x] [ ] [ ] [ ] [ ] other: develop integration concepts between people

[x] [ ] [ ] [ ] [ ] promote development of manufacturing system documentation

What is the main strength of this architecture?

It suggests an overall, generically applicable structure for designing an integrated Production Management System.

To your knowledge which essential or important goals (see Question 5) are specifically not adequately addressed by this architecture?

Information technology infrastructure.

\subsection{MODELLING}

\subsubsection{What kinds of models describe this architecture?}

Please characterize the models which this architecture requires to be produced? (The table for your answers has been broken into four parts because it had too many columns - see following pages).

Characterize the corresponding modelling languages used to express the models. NB. For the purposes of collecting information we have ordered these tables by the models and not by the modelling languages. Note that because the same modelling language is often used for more than one model, it is enough to characterize the language only once. However, it is expected that the questions about the language's adequacy for each separate type of model will be answered separately.

Important: the descriptions capturing requirements, designs, etc, are produced in many, very different forms (formal mathematical models, graphs, natural language, tables). We use the word 'model' to refer to all of these forms. 


\begin{tabular}{|c|c|c|c|c|c|}
\hline Model $^{\mathrm{a}}$ & $\begin{array}{l}\text { Modelling } \\
\text { Language }^{\mathrm{b}}\end{array}$ & $\begin{array}{l}\text { Degree of } \\
\text { formality }^{c}\end{array}$ & $\begin{array}{l}\text { Should it be } \\
\text { executable? }\end{array}$ & $\begin{array}{l}\text { Is it exe- } \\
\text { cutable? }\end{array}$ & $\begin{array}{l}\text { Demonstra- } \\
\text { ted feasibil- } \\
\text { ity }\end{array}$ \\
\hline $0 .^{\mathrm{e}}$ & GRAI grid & $S$ & $\mathrm{Y}^{*}$ & & \\
\hline $1 .^{\mathrm{f}}$ & GRAI grid & $S$ & $\mathrm{Y}^{*}$ & & \\
\hline $2^{g}$ & GRAICO & $S$ & $\mathrm{Y}^{*}$ & & \\
\hline $3 .^{\mathrm{h}}$ & ER & $\mathrm{F}$ & $\mathrm{Y}^{*}$ & & \\
\hline 4. ${ }^{\mathrm{i}}$ & IDEF0 & $S$ & $\mathrm{Y}^{*}$ & & \\
\hline $5 . j$ & IDEF0 & $S$ & $\mathrm{Y}^{*}$ & & \\
\hline $6 .^{\mathrm{k}}$ & ER & $S$ & $\mathrm{Y}^{*}$ & & \\
\hline 7. & GRAI Grid & $S$ & & & \\
\hline $8 .^{m}$ & Grai nets & $\mathrm{S}$ & & & \\
\hline 9. ${ }^{\mathrm{n}}$ & IDEF $^{\circ}$ & $S$ & & & \\
\hline
\end{tabular}

a. Please add rows as necessary. E.g., 'functional requirements model,' 'organizational design model', etc. Note that if models are substantially different on various levels of genericity then you are asked to enter these as separate models.

b. Here 'language' is used in general sense, e.g., ER, Lotos, IDEF0, natural language, Petri net, etc.

c. Please rate: $\mathrm{I}=$ Informal, $\mathrm{S}=$ Structured but the expressive power of the formal part is not adequate (missing information being added in natural language), $\mathrm{F}=$ Formal mathematical model, with formal semantics.

$\mathrm{d}$. This is the feasibility of producing an adequate model using this language, $\mathrm{P}=$ Practically demonstrated, $\mathrm{T}=$ Demonstrated in theory, or only $\mathrm{C}=$ Conjectured. Please add further comments in footnotes and on separate pages if necessary.

e. Global conceptual decisional model

f. Detailed conceptual decisional model

g. Operations model

h. Information model

i. Functional model

j. Conceptual physical model

k. Structural information model

1. Global structural decisional model 
m. Detailed structural decisional model

n. Structural physical model

o. IDEF0 with time and synchronization

* Under development

\begin{tabular}{lll}
\hline Model & $\begin{array}{l}\text { Adequacy }^{\mathrm{a}} \text { of } \\
\text { modelling language }\end{array}$ & $\begin{array}{l}\text { Is there any } \text { related }^{\mathrm{b}} \\
\text { modelling language? }\end{array}$ \\
\hline $0 .^{\mathrm{c}}$ & $\mathrm{Y}$ & $\mathrm{N}$ \\
$1 .^{\mathrm{c}}$ & $\mathrm{Y}$ & $\mathrm{N}$ \\
$2 .^{\mathrm{d}}$ & $\mathrm{Y}$ & $\mathrm{N}$ \\
$3 .^{\mathrm{e}}$ & $\mathrm{Y}$ & $\mathrm{N}$ \\
$4 .^{\mathrm{f}}$ & $\mathrm{Y}$ & $\mathrm{N}$ \\
$5 . \mathrm{g}$ & $\mathrm{P}$ & $\mathrm{N}$ \\
\hline
\end{tabular}

a. $\mathbf{P}=$ Poor, $\mathrm{A}=$ Adequate, $\mathrm{G}=\mathrm{Good}, \mathrm{V}=$ Very good; please comment on problems, limitations in footnote. E.g., over-formalized, not formal enough, certain detail not expressible, forces unnecessary decision to be taken too early, etc.

b. If the language used is not a standard and there is a related standard, could you comment, in a footnote, why the selected language is used instead of a standard one?

c. Apparently there does not exist a standardized language adapted to the decisional model.

d. Petri nets are used but we think that GRAI CO is more complete.

e. We think that the ER model is a pseudo standard therefore we use it.

f. We think that IDEF0 is a pseudo standard therefore we use it.

g. Today there is no precise tool to model the physical system.

2, 3, 4: Although not standardized these languages are widely used in industry.

\begin{tabular}{lllll}
\hline Model & $\begin{array}{l}\text { Verifiability }^{\mathrm{a}} \\
\text { of model }\end{array}$ & $\begin{array}{l}\text { Could any } \\
\text { alternative lan- } \\
\text { guage be used? }\end{array}$ & $\begin{array}{l}\text { Can complete- } \\
\text { ness be } \\
\text { achieved? }\end{array}$ & $\begin{array}{l}\text { Supported by } \\
\text { CASE tool? }\end{array}$ \\
\hline 0. & VA & no & $\mathrm{N}$ & CAGIM \\
1. & VH & IDEF0 & N & CAGIM \\
2. & VH & Petri net & N & \\
\hline
\end{tabular}




\begin{tabular}{lllll}
\hline 3. & VA & NIAM, IDEF1 & $\mathrm{N}$ & $\begin{array}{l}\text { CAGIM and } \\
\text { many others }\end{array}$ \\
4. & $\mathrm{VH}$ & $\begin{array}{l}\text { Functional } \\
\text { diagram }\end{array}$ & $\mathrm{N}$ & $"$ \\
5. & $\mathrm{VH}$ & $\begin{array}{l}\text { Simulation } \\
\text { languages }\end{array}$ & $\mathrm{N}$ & $"$ \\
\hline
\end{tabular}

a. Rate: $\mathrm{VH}=$ model verifiable by human expert, following a method; VA =automatic or interactive verification is possible; $\mathrm{VK}=$ automatic or interactive verification is possible if large knowledge base present; $\mathrm{VE}=$ validation possible only by experiments (real or simulation).

b. $\mathrm{Y}=$ yes, a complete mathematical model can be developed from which all necessary design features can be calculated, $\mathrm{N}=$ no, if not, could you tell what provision can be made to substitute for the lack of mathematical completeness?

c. Please provide names of CASE tools (or write $\mathrm{Y}=\mathrm{yes}$ if name is unknown to you), $\mathrm{N}=$ no, $\mathrm{U}=$ unknown (no information). Note that question 20 will separately ask about the adequacy of the CASE/CAE tools listed.

\begin{tabular}{lll}
\hline $\begin{array}{l}\text { Model }^{\text {a }} \\
\text { 2. }\end{array}$ & $\begin{array}{l}\text { Adequacy of language for people } \\
\text { who should use/interpret the } \\
\text { model }^{\text {b }}\end{array}$ & $\begin{array}{l}\text { Adequacy of language for those } \\
\text { who should produce the model }\end{array}$ \\
\hline 1. & VG & VG \\
2. & A & G \\
3. & A & G \\
4. & VG & G \\
5. & VG & VG \\
\hline
\end{tabular}

a. Please add rows as necessary.

b. Please rate the modelling language $P=$ poor, $A=$ adequate, $G=$ good, $V=$ very good; please comment on problems, limitations in footnote if needed.

c. Please rate the modelling language $P=$ poor, $A=$ adequate, $G=$ good, $V=$ very good; please comment on problems, limitations in footnote if needed. 
12.2.2 How well does the architecture describe the operational characteristics of an enterprise in contrast with describing only its basic design feature?

[x] operational characteristics can be derived from the design features (e.g. through simulation model)

\subsubsection{Formalism}

Do you think formal methods (with rigorously defined syntax and semantics) are needed to describe and interpret the architecture under discussion and the representation of particular systems by it?

[ ] necessary

[ ] desirable

[ ] possible

[x] not possible at the moment

Please comment on what areas you have applied or intend to apply formal methods?

As apparent from answers to Question 17, the information model is based on ER which can be considered as a formal model.

Could there be a formal canonical view developed together with a modelling language which would subsume all of the ones used? If yes, please specify what should be the characteristics of such a language:

Manufacturing System modelling needs two levels, descriptive and formal. Starting from reality we develop a descriptive model first (to start with a formal model seems to be too difficult). In our approach using our modelling tools, we develop a model of the reality. The objective is to simplify but to keep the main features. From this descriptive model we elaborate a formal model in order to improve the design. We have used this approach for simulation i.e. first we developed our IDEFO model, then 'Activities' model (CSL-CAPS). We are developing our research in this direction.

Do you think that the scope of the formal methods is broad enough to capture what you want to describe?

No answer provided

Can people who need to deal with these models easily relate to these formalisms?

No answer provided 


\subsubsection{Verification support}

How extensively are Computer-aided Engineering (CAE) tools available to verify the prescribed models?

[x] some support for the following models: All, limited: GRAICO

Do you think it is necessary to have CAE tools to support the methodology?

[x] yes, full support is needed

Are there any limitations to achieving the above?

No answer provided.

How well can the architecture be used to verify the completeness and adequacy of the overall design for an enterprise or any of its components? (Please comment on merits and problems.)

There is no conclusive evidence yet. We know that the architecture is good at the conceptual and structural levels.

\subsubsection{Economic questions}

How well does the associated methodology handle economic questions related to the enterprise described using its methods? (Give comments)

[x] well covered

[ ] some, but not full coverage of issues (what is lacking?)

[ ] not addressed in the modelling

[ ] no information Comments: Economic Tableau ('Tableaux de Board'). Economic evaluation tools currently being developed.

\subsection{METHODOLOGY}

\subsubsection{Does the architecture have a methodology connected to it?}

[ ] no

[x] yes (please give the name of the methodology) GIM

If possible, can you specify what are the components of the methodology?

1. Overall decisional modelling

2. Detailed decisional modelling 
3. Physical view design

4. Information systems design

5. User-oriented design

6. Technically oriented design

How complete is the methodology?

[ ] this is a complete methodology, covering all aspects of enterprise engineering activity

[x] the methodology is a collection of methods/logical techniques (but only separate methodologies are available for the individual modelling tasks)

[ ] the methodology is planned to be a complete one

Does the methodology address the human factor in the enterprise?

[x] treats the necessary human organization

[ ] skill levels for operating personnel

[x] training requirements

[x] treats teams partially

[ ] treats individual workers

\subsubsection{Validation status of the methodology}

Was the methodology validated

[x] in implemented industry projects/systems

[ ] in experimental systems

[ ] other: (Could you give references?)

No answer provided

\subsubsection{Maturity of the methodology}

The methodology has been

[x] successfully taught by others than its developers

[x] successfully applied by other than its developers

[x] repeatedly applied by its developers

[x] shown to work by its developers

[ ] other (e.g. 'under development') 
12.3.4 Scope of the methodology

\begin{tabular}{|c|c|c|c|c|}
\hline $\begin{array}{c}\text { [] extensive } \\
\text { coverage }\end{array}$ & $\begin{array}{c}{[] \text { some }} \\
\text { coverage }\end{array}$ & $\begin{array}{c}{[] \text { no }} \\
\text { coverage }\end{array}$ & $\begin{array}{c}{[] \text { no }} \\
\text { information }\end{array}$ & $\begin{array}{c}\text { [] not } \\
\text { applicable }\end{array}$ \\
\hline
\end{tabular}

Example

Check appropriate fields of the table.

\begin{tabular}{|c|c|c|c|}
\hline $\begin{array}{l}\text { Activities and } \\
\text { related } \\
\text { methods to }\end{array}$ & $\begin{array}{l}\text {...common to all } \\
\text { systems in the } \\
\text { scope }\end{array}$ & $\begin{array}{l}\text {...common to a } \\
\text { family of systems } \\
\text { in the scope } \\
\text { (which one?) }\end{array}$ & $\begin{array}{l}\text {...of individual } \\
\text { systems }\end{array}$ \\
\hline $\begin{array}{l}\text { produce } \\
\text { requirements... }\end{array}$ & $[\mathrm{x}][\mathrm{]}][\mathrm{]}] \mathrm{]}]$ & {$[\mathrm{x}][\mathrm{]}][][][]$} & {$[x][][][][]$} \\
\hline $\begin{array}{l}\text { produce the } \\
\text { design } \\
\text { specifications... }\end{array}$ & {$[x][][][][]$} & $[\mathrm{x}][\mathrm{]}][\mathrm{]}] \mathrm{]}]$ & {$[x][][][][]$} \\
\hline $\begin{array}{l}\text { produce the } \\
\text { detailed design... }\end{array}$ & {[][][][]$[x]$} & {$[\mathrm{J}] \mathrm{]}[\mathrm{]}] \mathrm{]}[\mathrm{x}]$} & {$[\mathrm{J}[\mathrm{]}] \mathrm{]}[\mathrm{x}]$} \\
\hline $\begin{array}{l}\text { produce the } \\
\text { system... }\end{array}$ & {[]$[x][][][]$} & {$[\mathrm{]}[\mathrm{x}][\mathrm{]}][\mathrm{]}[\mathrm{]}$} & {$[\mathrm{e}][\mathrm{x}][\mathrm{]}][\mathrm{]}]$} \\
\hline $\begin{array}{l}\text { produce the } \\
\text { operational and } \\
\text { maintenance } \\
\text { methods.... }\end{array}$ & {$[\mathrm{x}][\mathrm{]}][][][]$} & {$[x][][][][]$} & {$[x][][][][]$} \\
\hline
\end{tabular}

Example: check 'extensive coverage' box in upper right hand corner if the methodology extensively tackles 'activities and related methods to produce the requirements of individual systems,' to be read from the table as:

Activities and related

methods to

produce the requirements ......of individual systems.

Note 1: If the methodology is partially complete in any of these respects pleased add footnote to the box you checked.

Note 2: You can add additional model types below, or on a separate sheet, if you feel that the above categories are not exhaustive: 


\subsubsection{Presentation of the methodology}

\begin{tabular}{|c|c|c|c|c|c|c|}
\hline $\begin{array}{c}{[]} \\
\text { extensive } \\
\text { planned }\end{array}$ & $\begin{array}{c}{[]} \\
\text { some } \\
\text { planned }\end{array}$ & $\begin{array}{c}{[]} \\
\text { extensive } \\
\text { now }\end{array}$ & some now & $\begin{array}{c}{[]} \\
\text { none }\end{array}$ & $\begin{array}{c}{[]} \\
\text { no info. }\end{array}$ & $\begin{array}{c}{[]} \\
\text { not } \\
\text { applicable }\end{array}$ \\
\hline
\end{tabular}

[ ] [ ] [x] [ ] [ ] [ ] [ ] handbook or collection of handbooks

[ ] [ ] [ ][x][ ][ ][ ] teaching material

$[\mathrm{]}[\mathrm{]}[\mathrm{x}][\mathrm{]}][][\mathrm{]}] \mathrm{]}$ organizational procedures

[ ] [ ] [x] [ ] [ ] [ ] [ ] CASE tool support for individuals

[ ] [ ] [x][ ] [ ] [ ] [ ] project database

[ ] [ ] [ ] [x] [ ] [ ] [ ] CASE tool support for project team

[ ] [ ] [ ] [x] [ ] [ ] [ ] any other form? metaformalism to describe the

modelling languages

\subsubsection{Genericity}

We want to know how big the gap is between the methodology as presented (see Question 26) and the way it is applied in particular projects.

[x] the methodology describes general procedures only

[ ] the methodology is supported by a collection of application examples/ cookbook (In the future)

\subsubsection{Quality of the methodology}

Please rate the methodology from the following aspects:

\begin{tabular}{|c|c|c|c|c|c|}
\hline poor & average & good & excellent & no info. & N/A \\
[] & {[]} & {[]} & {[]} & {[]} & {[]} \\
\hline
\end{tabular}

Example

[ ] [ ] [ ] [x] [ ] [ ] [ ] support of cooperative teamwork

[ ] [ ] [ ] [x] [ ] [ ] [ ] support of work with multiple organizations

[ ] [ ] [ ] [x] [ ] [ ] [ ] flexibility in terms of project size

[ ] [ ] [x] [ ] [ ] [ ] [ ] flexibility in terms of innovativity of project

[ ] [ ] [ ] [ ] [ ] [ ] [x] quality control of project (not yet)

[ ] [ ] [x] [ ] [ ] [ ] [ ] CAE tools support (not yet) 